ORIGINAL ARTICLE

\title{
Heart failure in non ST-elevation myocardial infarction (NSTEMI) patients presenting in Faisalabad Institute of Cardiology.
}

\author{
Ali Sajjad ${ }^{1}$, Nouman Arif $^{2}$, Rehan Riaz ${ }^{3}$, Naeem Hameed ${ }^{4}$
}

Article Citation: Sajjad A, Arif N, Riaz R, Hameed N. Heart failure in non ST-elevation myocardial infarction (NSTEMI) patients presenting in Faisalabad Institute of Cardiology. Professional Med J 2022; 29(3):328-334. https://doi.org/10.29309/TPMJ/2022.29.03.6986

\begin{abstract}
Objective: To determine the frequency of heart failure in non ST-elevation myocardial infraction (NSTEMI) patients presenting in Faisalabad Institute of Cardiology. Study Design: Descriptive, Cross Sectional study. Setting: Cardiac Emergency, Faisalabad Institute of Cardiology, Faisalabad. Period: July 2019 to January 2020. Results: A total of 150 patients between 18 to 75 years of either gender admitted with NSTEMI were included. Patients with active cancer or any malignant tumor or autoimmune inflammatory disease, other than NSTEMI, such as STEMI, unstable angina, takotsubo cardiomyopathy and myocarditis, liver and renal failure were excluded. Each patient was assessed by history taking and clinical examination to ensure the diagnosis of heart failure. Smoking, hypertension, dyslipidemia, diabetic, previous history of MI, CABG and pPCl were noted. Age range in this study was from 18 to 75 years with mean age of $44.28 \pm 7.70$ years. Majority of the patients $88(58.67 \%)$ were between 18 to 45 years of age. Out of the 150 patients, $116(77.33 \%)$ were male and $34(22.67 \%)$ were females with ratio of $3.4: 1$. Frequency of heart failure in non-ST elevation myocardial infraction (NSTEMI) patients was found in 20 (13.33\%) patients. Conclusion: This study concluded that there is high frequency of heart failure in non-ST elevation myocardial infraction (NSTEMI) patients.
\end{abstract}

Key words: $\quad$ Heart Failure, Myocardial Infarction, Non ST Elevation.

\section{INTRODUCTION}

Acute coronary syndrome (ACS) refers to a group of signs and symptoms with underlying defect in blood supply of heart that can lead to malfunction of heart muscles leading ultimate to their necrosis. ${ }^{1}$ Acute coronary syndrome (ACS) has three modes of presentation including STEMI (30\%), NSTEMI (25\%), or Unstable angina $(38 \%))^{2,3}$ Patients of ACS present with chest pain which has special character indicative of cardiac origin. It can also be shortness of breath, sweating and nausea. Different types of presentations of ACS can be differentiated through ECG findings. ${ }^{4}$ The diagnostic criteria of ACS comprise on the ischemic symptoms like chest pain at rest, ECG changes, and raised cardiac biomarkers, of which cardiac troponin is the most important. ${ }^{5}$

Any form of acute coronary syndrome effects myocardial blood supply. Myocardium need to be viable with patent blood supply for proper functioning. Any mechanism impairing blood supply will lead to impaired function of myocardium. Impaired myocardial function leads to heart failure which is most lethal complication of Ml. Heart failure is quite common in STEMI patients. Heart failure in NSTEMI and unstable angina seems less frequent but usually quite high number is seen in clinical practice. Heart Failure in patients of STEMI is well studied but HF in NSTEMI is not well known along with its prognosis. ${ }^{6}$ GRACE registry shows almost equal evidence of HF in STEMI (15.6\%) and NSTEMI (14.7\%) whereas UA has lesser mortality with HF. As the incidence of non-STEMI is increasing, the need of the time is to assess determinants and the impact of $\mathrm{HF}$ in NSTEMI. ${ }^{7}$

Left ventricular systolic dysfunction (LVSD) as a result of Myocardial infarction is quite frequent
1. FCPS (Card), Assistant Professor Cardiology, Faisalabad Institute of Cardiology Faisalabad. 2. MBBS, Medical Officer, Faisalabad Institute of Cardiology Faisalabad.

3. FCPS (Card), Assistant Professor Cardiology, Faisalabad Institute of Cardiology Faisalabad.

4. FCPS (Card), Resident FCPS Interventional Cardiology, Faisalabad Institute of Cardiology Faisalabad.
Correspondence Address:

Dr. Rehan Riaz

Department of Cardiology

Faisalabad Institute of Cardiology Faisalabad. rehanriazdab@gmail.com

Article received on:

$27 / 11 / 2021$

Accepted for publication: 
and is present in more than $50 \%$ cases. Out of these almost $25 \%$ develop Heart failure. With advancement in myocardial revascularization techniques and evidence based practice, the rate of $\mathrm{HF}$ has reduced to $50 \%$. But still this complication is challenging for clinicians, as $80 \%$ of morbidity and mortality in myocardial infarction occur with heart failure. ${ }^{8}$

Burden of HF along with its management strategy is of prime importance in cardiology as it shares high impact on outcome of MI in terms of mortality. It was found in one study that Survival is higher in patients without congestive heart failure than with congestive heart failure patients..$^{9,10}$

Ahit MC, et al. reported the $10.6 \%$ frequency of $\mathrm{HF}$ in NSTEMI patients with old age, female gender, very high heart rate, higher presenting heart rate, diabetes, hypertension and previous history of $\mathrm{MI}$ are significant risk factors noted. ${ }^{11,12}$ Kaul $\mathrm{P}$, et al reported $13.6 \%$ patient of HF in STEMI and $14.8 \%$ patients of HF with NSTEMI $(P<.01) .{ }^{13}$ Roubin SR, et al reported it to be $10.5 \%$ and it was associated with high mortality rate. ${ }^{14,15}$ Franco $E$, et al reported that up to $15 \%$ of patients with NSTEMI present at admission with heart failure and its management guidelines are still limited and need further discussion. ${ }^{16}$

Limited data is available about the incidence of heart failure in patients of NSTEMI in Pakistan. As NSTEMI is a common presentation in cardiac emergencies and heart failure along with NSTEMI leads to significant morbidity and mortality, we have designed this study to determine the frequency of heart failure in NSTEMI patients. Early diagnosis and management of heart failure in NSTEMI patients can decrease the length of stay in hospital, time of recovery, decrease morbidity and decrease the treatment cost.

To determine the frequency of heart failure in non-ST elevation myocardial infraction (NSTEMI) patients

\section{OPERATIONAL DEFINITIONS \\ Non-ST elevated myocardial infraction (NSTEMI)}

Any patient presenting with chest pain along with changes in ECG including ST segment depression, $T$ wave inversion, no progression to $Q$ waves and raised cardiac biomarkers including Troponin I > $0.3 \mathrm{ng} / \mathrm{ml}$, Troponin T > $100 \mathrm{ng} / \mathrm{L}$ ), was labeled as having NSTEMI.

\section{Heart Failure: 105}

Any patient presenting with Killip classes II to IV was labeled as having heart failure:

- Class II: Patients with crepitations in the lungs, elevated jugular venous pressure (JVP) and 3rd heart sound.

- Class III: Patients with frank acute pulmonary edema.

- Class IV: Patients in cardiogenic shock (Systolic BP < 90 with inotropic support and < 80 without ionotropic support along with cold clammy extremities, pallor and confusion) and evidence of peripheral vasoconstriction (sweating, cyanosis, oliguria-measured as urine output less than $400 \mathrm{ml}$ per 24 hour in adults). It was defined as coronary catheterization (angiography/angioplasty) using trans-radial approach.

\section{MATERIAL AND METHODS}

The study was conducted at cardiac emergency, Faisalabad Institute of Cardiology, Faisalabad from 8th July 2019 to 7 th January 2020 . The study design was Descriptive, Cross sectional study Non-probability consecutive sampling technique was adopted. The Sample size of 150 by taking $5 \%$ level of significance, $5 \%$ margin of error and taking percentage of heart failure in NSTEMI as $10.6 \% .^{9}$

\section{Inclusion Criteria}

1. All patients between 18 to 75 years of either gender admitted with NSTEMI were included in the study.

2. Patients with or without past history of Ischemic heart disease.

\section{Exclusion Criteria}

1. Patients with active cancer or any malignant 
tumor or autoimmune inflammatory disease

2. Patients with final diagnosis other than NSTEMI, such as STEMI, unstable angina, takotsubo cardiomyopathy and myocarditis.

3. Patients with liver, renal failure or with acute stroke.

After informed consent from the patients those fulfilling the operational definitions and the inclusion criteria were enrolled in the study. Each patient was assessed by history taking and clinical examination to ensure the diagnosis of heart failure. Smoking, hypertension, dyslipidemia, diabetic, previous history of MI, CABG and $\mathrm{pPCl}$ were noted. Relevant lab investigations and radiological investigations was sent to the relative departments. Age, weight, height, respiratory rate, blood pressure, gender, signs and symptoms of heart failure were noted. Patients who developed HF or pulmonary edema were also noted. Quantitative and qualitative variables were entered into the predesigned proforma.

\section{Statistical Analysis}

The data was analyzed using SPSS version 24.0. For qualitative variables Frequency and percentage were calculated. These include gender, smoking history, dyslipidemia, diabetes, previous history of $\mathrm{Ml}$, previous history of $\mathrm{PCl}$, various signs and symptoms of heart failure, Killip class and heart failure at presentation. For the quantitative variables like weight, height, respiratory rate, BMI, blood pressure, troponin I, and LVEF, mean \pm SD were calculated.

Effect modifiers like age, gender, smoking history, dyslipidemia, diabetic, previous history of $\mathrm{MI}$, previous history of $\mathrm{pPCl}$ and $\mathrm{BMI}$ were stratified to know the effect of these on the outcome, through chi square ( $p<0.05$ was considered significant).

\section{RESULTS}

Patients included in this study were 18 to 75 years with mean age of $44.28 \pm 7.70$ years. 88 (58.67\%) were between 18 to 45 years of age. Out of the 150 patients, 116 (77.33\%) were male and 34 (22.67\%) were females (Figure-2). Distribution of patients with other confounding variables is shown in Table-l.
Frequency of heart failure in NSTEMI patients was found in 20 (13.33\%) patients as shown in Figure-1.

When stratification was done for age groups with respect to heart failure, it was found that there was no significant difference of heart failure between different age groups as shown in TableII while gender stratification did not showed statistically significant difference. Stratification of heart failure with respect to BMI showed no statistically significant difference. Table-III, IV and $\mathrm{V}$ show the stratification of heart failure with respect to diabetes mellitus, dyslipidemia and smoking respectively. Table-VI \& VII have shown the stratification of heart failure with respect to previous history of $\mathrm{Ml}$ and previous history of $\mathrm{pPCl}$ respectively.

\begin{tabular}{|l|c|c|c|}
\hline $\begin{array}{c}\text { Confounding } \\
\text { Variables }\end{array}$ & & Frequency & \%age \\
\hline \multirow{2}{*}{ BMl $(\mathrm{kg} / \mathrm{m} 2)$} & $\leq 30$ & 92 & 61.33 \\
\cline { 2 - 4 } & $>30$ & 58 & 38.67 \\
\hline \multirow{2}{*}{$\begin{array}{l}\text { Diabetes } \\
\text { mellitus }\end{array}$} & Yes & 73 & 48.67 \\
\hline \multirow{2}{*}{ Dyslipidemia } & Yes & 77 & 51.33 \\
\cline { 2 - 4 } & No & 64 & 57.33 \\
\hline \multirow{2}{*}{ Smoking } & Yes & 93 & 62.67 \\
\hline \multirow{2}{*}{$\begin{array}{l}\text { Previous } \\
\text { history of MI }\end{array}$} & No & 57 & 58.0 \\
\hline Previous & No & 61 & 40.67 \\
\hline history of $p P C l$ & No & 30 & 59.33 \\
\cline { 2 - 4 } & & 120 & 80.0 \\
\hline
\end{tabular}

Table-I. Distribution of patients with other confounding variables. $(n=150)$

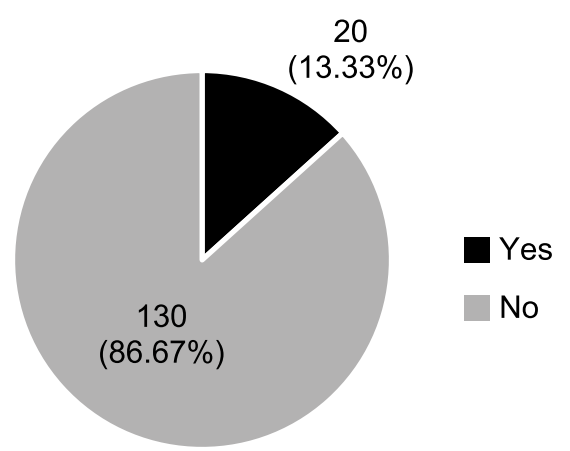

Figure-1. Frequency of heart failure in non-ST elevation myocardial infraction (NSTEMI). 


\begin{tabular}{|c|c|c|c|}
\hline \multirow{2}{*}{ Age (years) } & \multicolumn{2}{|c|}{ Heart Failure } & \multirow{2}{*}{ P-Value } \\
\hline & Yes & No & \\
\hline $18-45$ & 11 & 77 & \multirow{2}{*}{0.721} \\
\hline $46-75$ & 09 & 53 & \\
\hline
\end{tabular}

Table-II. Stratification heart failure with respect to age groups.

\begin{tabular}{|l|c|c|c|}
\hline \multirow{2}{*}{$\begin{array}{c}\text { Diabetes } \\
\text { Mellitus }\end{array}$} & \multicolumn{2}{|c|}{ Heart Failure } & \multirow{2}{*}{ P-Value } \\
\cline { 1 - 3 } Yes & Yes & No & \\
\hline No & 11 & 62 & \multirow{2}{*}{0.543} \\
\hline
\end{tabular}

Table-III. Stratification of heart failure with respect to DM.

\begin{tabular}{|l|c|c|c|}
\hline \multirow{2}{*}{ Dyslipidemia } & \multicolumn{2}{|c|}{ Heart Failure } & \multirow{2}{*}{ P-Value } \\
\cline { 2 - 3 } & Yes & No & \\
\hline Yes & 10 & 76 & 0.476 \\
\hline No & 10 & 54 & 0.47 \\
\hline
\end{tabular}

Table-IV. Stratification of heart failure with respect to dyslipidemia.

\begin{tabular}{|l|c|c|c|}
\hline \multirow{2}{*}{ Smoking } & \multicolumn{2}{|c|}{ Heart Failure } & \multirow{2}{*}{ P-Value } \\
\cline { 1 - 3 } & Yes & No & \\
\hline Yes & 10 & 83 & 0.235 \\
\hline No & 10 & 47 & \\
\hline
\end{tabular}

Table-V. Stratification of heart failure with respect to smoking.

\begin{tabular}{|l|c|c|c|}
\hline \multicolumn{1}{|c|}{$\begin{array}{c}\text { Previous } \\
\text { History of MI }\end{array}$} & \multicolumn{2}{|c|}{ Heart Failure } & P-Value \\
\hline Yes & Yes & No & \\
\hline No & 12 & 49 & 0.059 \\
\hline
\end{tabular}

Table-VI. Stratification of heart failure with respect to previous history of MI.

\begin{tabular}{|l|c|c|c|}
\hline \multicolumn{1}{|c|}{$\begin{array}{c}\text { Previous } \\
\text { History of pPCI }\end{array}$} & \multicolumn{2}{|c|}{ Heart Failure } & P-Value \\
\hline Yes & Yes & No & \\
\hline No & 04 & 26 & 1.000 \\
\hline
\end{tabular}

Table-VII. Stratification of heart failure with respect to previous history of $\mathrm{pPCl}$.

\section{DISCUSSION}

Heart failure (HF) is a common cardiovascular presentation and leads to significant contribution in national healthcare costs in the western world. ${ }^{17,18}$ Heart failure can be a result of multiple etiologies with ischemic heart disease being the most common along with myocardial diseases and valvular lesions. With developments in the field of cardiology and use of $\mathrm{PCl}$ as revascularization strategy, the incidence and outcome of heart failure has also been changed. Between 1996 and 2008 a Swedish registry (SWEDEHEART) showed a reduction in the incidence of $\mathrm{HF}$ from $50 \%$ to $28 \%{ }^{19}$ In a Canadian study, STEMI patients who develop HF had associated 1-year mortality of $9.9 \%{ }^{20}$

In our study, frequency of heart failure in NSTEMI patients was found in 20 (13.33\%) patients. Ahit $\mathrm{MC}$, et al. reported the $10.6 \%$ frequency of HF in NSTEMI patients with old age, female gender, very high heart rate, higher presenting heart rate, diabetes, hypertension and previous history of $\mathrm{Ml}$ are significant risk factors noted. ${ }^{11,12}$ Kaul $\mathrm{P}$, et al reported $13.6 \%$ patient of HF in STEMI and $14.8 \%$ patients of HF with NSTEMI $(P<.01) .{ }^{13}$ Roubin SR, et al reported it to be $10.5 \%$ and it was associated with high mortality rate. ${ }^{14,15}$ Franco $\mathrm{E}$, et al reported that up to $15 \%$ of patients with NSTEMI present at admission with heart failure and its management guidelines are still limited and need further discussion. ${ }^{16}$

In Japan 5429 STEMI patients showed HF hospitalization pf $4.4 \%$ per year in 1 st year followed by $1 \%$ per year. ${ }^{21}$ From 1990 to 1999 Velagaleti et al. did 5 years follow-up of MI patients and found that $14.8 \%$ of patients developed congestive $\mathrm{HF}^{22}$ In a Canadian study conducted between 1994 and 2000 , patients with $\mathrm{Ml}$ and who were 65 years or older without $\mathrm{HF}$ during their admission, $71 \%$ (3040/4291) developed HF by 5 years. ${ }^{23}$

A study showed incidence of heart failure after discharge to be $33 \% .{ }^{24}$ In another study, 10 years follow-up was done for patients of MI. It showed $22.4 \%$ incidence of heart failure within 1 month of admission and $12.4 \%$ had one admission for 10 years followup. ${ }^{25}$ Olmsted County (Minnesota, USA) study observed $41 \%$ incidence of HF in MI patients followed for 6.6 years. ${ }^{26} \mathrm{~A}$ Norwegian study showed, $17.1 \%$ developed in-hospital HF among 69,372 patients admitted with $\mathrm{Ml}$ and 1 year follow up showed $5.4 \% \mathrm{HF}^{27}$

Coronary artery involvement in NSTEMI also have correlation with development of Heart failure. Patients with Single vessel disease are less prone to have HF then those with two vessel and three vessel cor. Artery disease. One study showed 
similar results of HF in ACS patients with or without obstructive $C A D^{28}$ but that study included patient's $\geq 75$ years only. Myocardial injury in patients of heart failure there is rise in cardiac troponins which resemble $\mathrm{MI}^{29}$

The study of Mehta et $\mathrm{al}^{30}$, showed the incidence rates of $\mathrm{HF}$ at $24 \mathrm{~h}$ to be $2.7 \%$, at 7 days it was $4.9 \%$, and $6.3 \%$ at 6 months in OASIS- 2 trial. These were significantly lower than those mentioned in the GRACE registry. ${ }^{31}$ Patients in the OASIS-2 trial were at high risk of death or $\mathrm{MI}$ who developed HF than those without HF. HF patients were older, preferably female, and mostly diabetic, hypertensive, and with h/o prior Ml. These patients had similar high-risk characteristics as patients with HF in our study.

Out of GRACE registry ${ }^{32}$ the factors leading to increased incidence of HF in NSTE-ACS were evaluated. It was concluded that the incidence of HF was $13 \%$ and it was similar in patients with (14.7\%) and without (15.6\%) ST elevation MI. It was less in patients with UA (8.2\%). In SAVE study $^{33}$, majority of patients with LV systolic dysfunction showed no HF (60\%), in the VALIANT study $^{34}, 42 \%$ of patients with HF did not have LV systolic dysfunction (LVSD). In our study, we targeted the highest risk patients including postAMI patients having both clinical signs of HF and LVSD.

\section{CONCLUSION}

Our study concluded that there is high incidence of heart failure in patients of non-ST elevation myocardial infraction (NSTEMI). So, we recommend that these particular patients should be evaluated properly for heart failure and timely management is required in order to reduce the morbidity and mortality of these particular patients.

Copyright@ 29 Jan, 2022.

\section{REFERENCES}

1. Amsterdam EA, Wenger NK, Brindis RG, Casey DE, Ganiats TG, Holmes DR, et al. 2014 AHA/ACC guideline for the management of patients with non-st-elevation acute coronary syndromes: A report of the American College of Cardiology/American heart association task force on practice guidelines. Circulation. 2014; 130(25):344-426.

2. Roffi M, Patrono C, Collet JP. 2015 ESC Guidelines for the management of acute coronary syndromes in patients presenting without persistent ST-segment elevation: Task force for the management of acute coronary syndromes in patients presenting without persistent ST-segment elevation of the European society of cardiology (ESC). Eur Heart J. 2016; 37(3):267-315.

3. Chou R. Cardiac screening with electrocardiography, stress echocardiography, or myocardial perfusion imaging: Advice for high-value care from the American College of Physicians. Ann Intern Med. 2015; 162(6):438-47.

4. Bundhun PK, Shaik M, Yuan J. Choosing between Enoxaparin and Fondaparinux for the management of patients with acute coronary syndrome: A systematic review and meta-analysis. BMC Cardiovascular Disorders. 2017; 17(1):116.

5. Corcoran D, Grant P, Berry C. Risk stratification in non-ST elevation acute coronary syndromes: Risk scores, biomarkers and clinical judgment IJC 2015; 8:131-7.

6. McManus DD, Chinali M, Saczynski JS. 30-year trends in heart failure in patients hospitalized with acute myocardial infarction. Am J Cardiol 2011:107:353-9.

7. McManus DD, Gore J, Yarzebski J, Spencer F, Lessard $D$, Goldberg RJ, et al. Recent trends in the incidence, treatment, and outcomes of patients with STEMI and NSTEMI. Am J Med 2011:124:40-7.

8. Carillo S, Zhang Y, Fay R, Angioi M, Vincet J, Ahmed A, et al Heart failure with systolic dysfunction complicating acute myocardial infarction - differential outcomes but similar eplerenone efficacy by ST-segment or non-ST-segment elevation: A post hoc sub study of the EPHESUS trial. Cardiovasc Dis 2014; 107:149-57.

9. Juillière $Y$, Cambou JP, Bataille V, Mulak G, Galinier $M$, Gibelin $P$, et al. Heart failure in acute myocardial infarction, a comparison between patients with or without heart failure criteria from the FAST-MI registry. Rev esp cardiol. 2012; 65:326-33. 
10. Knežević B, Vasiljevic Z, Music L, Krivokapic L, Ljubic V, Tomic SC, et al Management of heart failure complicating acute coronary syndromes in Montenegro and Serbia Euro Heart J suppl 2014; 16:61-6.

11. Bahit MC, Lopes RD, Clare RM, Newby L.K, Pieper KS, Armstrong PW, et al. Heart failure complicating nonST-segment elevation acute coronary syndrome Heart failure 2013; 1:223-9.

12. Núñez-Gil IJ, Luaces M, Vivas D, Bordes S, Macaya C, Ortiz AF, et al. Mild heart failure is a mortality marker after a non-ST-segment acute myocardial infarction Euro J int med 2010; 21:439-43.

13. Kaul P, Ezekowitz JA, Armstrong PW, Leung BK, Savu $A$, Welsh RC, et al. Incidence of heart failure and mortality after acute coronary syndromes Am Heart J 2013;165:379-85.

14. Roubín SR, Cruz B, Abu Assi E, Juanatey G, Ramón J, Román $\mathrm{AV}$, et al. Risk stratification for the development of heart failure after acute coronary syndrome at the time of hospital discharge: Predictive ability of GRACE risk score J cardiol 2015; 66:224-31.

15. Kiljanek LR, Cheriyath $P$. Prediction of congestive heart failure as adverse outcome of non-st-elevation myocardial infarction Journal of cardiac failure 2009; 15:93-4.

16. Franco E, Gil N.IJ, Vivas D, Ruiz B, Ibañez B, Gonzalo $\mathrm{N}$, et al. Heart failure and non-ST-segment elevation myocardial infarction: A review for a widespread situation. Euro J intl med 2011; 22:533-40. 106.

17. Mosterd A, Hoes AW. Clinical epidemiology of heart failure. Heart 2007; 93:1137-46.

18. Ho JE, Enserro D, Brouwers FP, Kizer JR, Shah SJ, Psaty BM, Bartz TM, Santhanakrishnan R, Lee DS, Chan C, Liu K. Predicting heart failure with preserved and reduced ejection fraction: The international collaboration on heart failure subtypes. Circulation: Heart Failure. 2016 Jun; 9(6):e003116.

19. Desta L, Jernberg T, Löfman I. Incidence, temporal trends, and prognostic impact of heart failure complicating acute myocardial infarction. The SWEDEHEART registry (Swedish Web-System for Enhancement and Development of EvidenceBased Care in Heart Disease Evaluated According to Recommended Therapies): A study of 199,851 patients admitted with index acute myocardial infarctions, 1996 to 2008. JACC Heart Fail 2015; 3:23442.
20. Kaul P, Ezekowitz JA, Armstrong PW. Incidence of heart failure and mortality after acute coronary syndromes. Am Heart J 2013; 165:379-85.

21. Taniguchi $T$, Shiomi $H$, Morimoto $T$. Incidence and prognostic impact of heart failure hospitalization during follow-up after primary percutaneous coronary intervention in st-segment elevation myocardial infarction. Am J Cardiol 2017; 119:172939.

22. Velagaleti RS, Pencina MJ, Murabito JM. Longterm trends in the incidence of heart failure after myocardial infarction. Circulation 2008; 118:2057-62.

23. Ezekowitz JA, Kaul P, Bakal JA. Declining in-hospital mortality and increasing heart failure incidence in elderly patients with first myocardial infarction. J Am Coll Cardiol 2009; 53:13-20.

24. Torabi A, Cleland JG, Khan NK. The timing of development and subsequent clinical course of heart failure after a myocardial infarction. Eur Heart $J$ 2008; 29:859-70.

25. Najafi F, Dobson AJ, Hobbs M. Late-onset heart failure after myocardial infarction: Trends in incidence and survival. Eur J Heart Fail 2008; 10:765-71.

26. Hellermann JP, Jacobsen SJ, Redfield MM. Heart failure after myocardial infarction: Clinical presentation and survival. Eur J Heart Fail 2005; 7:119-25.

27. Sulo G, Igland J, Nygård $O$, Vollset SE, Ebbing $M$, Poulter N, Egeland GM, Cerqueira C, Jørgensen T, Tell GS. Prognostic impact of in $\square$ hospital and postdischarge heart failure in patients with acute myocardial infarction: A nationwide analysis using data from the Cardiovascular Disease in Norway (CVDNOR) Project. Journal of the American Heart Association. 2017 Mar 15; 6(3):e005277.

28. Wong V, Farah A, von Korn H, Memisevic N, Richter S, Tukhiashvili $K$, et al. Patients $\geq 75$ years with acute coronary syndrome but without critical epicardial coronary disease: Prevalence, characteristics, and outcome. J Geriatr Cardiol. 2015; 12:11-6.

29. Thygesen K, Alpert JS, Jaffe AS, Simoons ML, Chaitman $B R$, White HD, et al. Third universal definition of myocardial infarction. Eur Heart J. 2012; 33:2551-67.

30. Mehta SR, Eikelboom JW, Demers C, Maggioni AP, Commerford PJ, Yusuf $S$. Congestive heart failure complicating non-ST segment elevation acute coronary syndrome: Incidence, predictors, and clinical outcomes. Can J Physiol Pharmacol 2005; 83:98-103. 
31. Steg PG, Goldberg RJ, Gore J. Baseline characteristics, management practices, and in-hospital outcomes of patients hospitalized with acute coronary syndromes in the Global Registry of Acute Coronary Events (GRACE). Am J Cardiol 2002; 90:358-363.

32. Steg PG, Dabbous $\mathrm{OH}$, Feldman LJ. Determinants and prognostic impact of heart failure complicating acute coronary syndromes: Observations from the Global Registry of Acute Coronary Events (GRACE). Circulation 2004; 109:494-499.
33. Pfeffer MA, Braunwald E, Moye LA. Effect of captopril on mortality and morbidity in patients with left ventricular dysfunction after myocardial infarction. Results of the survival and ventricular enlargement trial. The SAVE Investigators N Engl J Med 1992; 327:669-677.

34. Velazquez EJ, Pfeffer MA, McMurray JV. VALsartan In Acute myocardial iNfarcTion (VALIANT) trial: Baseline characteristics in context Eur $\mathrm{J}$ Heart Fail 2003; 5:537-544.

\section{AUTHORSHIP AND CONTRIBUTION DECLARATION}

\begin{tabular}{|c|c|c|c|}
\hline No. & Author(s) Full Name & Contribution to the paper & Author(s) Signature \\
\hline 1 & Ali Sajjad & Data collection / Manuscript & kisaypar \\
\hline 2 & Nouman Arif & $\begin{array}{l}\text { writing. } \\
\text { Data collection / Manuscript } \\
\text { writing. }\end{array}$ & $2+7$ \\
\hline 3 & Rehan Riaz & $\begin{array}{l}\text { Data collection / Manuscript } \\
\text { writing. }\end{array}$ & \\
\hline 4 & Naeem Hameed & Proof Reading. & \\
\hline
\end{tabular}

